\title{
Defective neutrophil function in low-birth-weight, premature infants
}

\author{
H Al-hadithy, iE AdDison, AH Goldstone, JC CAWLEY, AND JC SHAW \\ From the Departments of Haematology and Paediatrics, University College Hospital, Gower Street, \\ London WCIE 6AU, UK
}

SUMMARY A whole-blood technique was used to measure simultaneously neutrophil migration, uptake, and killing of candida in 27 premature infants of low birth weight (less than $1500 \mathrm{~g}$ ). Neutrophil migration was consistently reduced, especially in the first two weeks of life. Phagocytosis was also reduced, particularly in the first week of life and in sick patients. Killing was usually normal, except in sick patients. The three functions were not altered when the test was performed in normal adult, rather than autologous, plasma, and the reduced migration and uptake are therefore the result of an intrinsic defect of the cell. The results clarify the previous controversy concerning neutrophil function in premature infants and provide an explanation for their increased susceptibility to infection.

Neonates, especially when premature and of low birth weight, have an increased susceptibility to infection. ${ }^{12}$ The basis of this infectious tendency has been the subject of considerable investigation and has been attributed to defects in both humoral and leucocyte defence mechanisms. ${ }^{1}$ The relative importance of these different defects is not clear, but defective neutrophil function is probably an important factor. ${ }^{2}$ Despite considerable investigation, however, there continues to be controversy concerning the precise neutrophil defect(s) present. ${ }^{3-22}$ This controversy may be attributable partly to the widely different techniques and organisms used but may also be a consequence of the incompleteness of many studies.

By means of an accurately reproducible wholeblood technique 2324 we have been able to study neutrophil migration, phagocytosis, and killing in autologous and control plasma with very small volumes of blood. This technique enables simultaneous assessment of these three aspects of neutrophil function in premature infants and at the same time avoids any artifact ${ }^{25}$ attributable to the leucocyte separation step used in most previous studies. In an attempt to clarify the present controversy concerning neutrophil function, a serial study of neutrophil migration, phagocytosis, and killing was performed in 22 of a series of 27 premature infants by means of a whole-blood technique.

Accepted for publication 10 September 1980

\section{Patients and methods}

\section{PATIENTS}

The subjects consisted of 27 premature infants of birth weight less than $1.5 \mathrm{~kg}$. They had a modal gestation age of 30 (range 27-34) weeks and a modal birth weight of 1200 (range 812-1400) g.

Five infants were studied only once, but the other patients were tested sequentially on two to 11 occasions. Testing was carried out at weekly intervals from as soon after birth as possible until discharge home. Patients who improved rapidly were often discharged after six to eight weeks. Therefore this study of inpatients resulted in the selection, after approximately eight weeks, of either less-well premature infants or infants of particularly low birth weight.

\section{NORMAL CONTROLS}

In all instances the patient result was compared with that of a normal adult control run on the same day in an identical fashion. In addition, cord blood from 12 normal full-term neonates was studied, and the results were found to be comparable with those obtained in adults.

\section{NEUTROPHIL FUNCTION}

Neutrophil migration and uptake and killing of candida were measured by a whole-blood technique described in detail elsewhere. ${ }^{23} 24$ This method enables the three functions to be measured in autologous and control plasma by diluting a $0.3 \mathrm{ml}$ blood sample to 
$1 \mathrm{ml}$ with Hanks's balanced salt solution. For each neutrophil function the test result was expressed as a ratio (fraction) of the normal adult control result run concurrently.

\section{HAEMATOLOGICAL PARAMETERS}

The haemoglobin and nucleated-cell count were measured on a Coulter $\mathbf{S}$ counter, and the absolute neutrophil count was derived by scoring the percentage neutrophils in a 100 -cell differential count. The haemoglobin ranged from $8 \cdot 1$ to $19 \cdot 2 \mathrm{~g} / \mathrm{dl}$, while the neutrophil count was between 0.55 and $26.7 \times$ $10^{9} / 1$.

\section{STATISTICAL METHODS}

The paired $t$ test, one sample $t$ test, and Pearson correlation techniques were used.

\section{Results}

\section{NEUTROPHIL MIGRATION}

The mean neutrophil migration in 103 samples from 27 neonates was $0.76 \pm 0.28$ when measured in autologous plasma (Fig. 1), which was not significantly different $(P=0.35)$ from control plasma $(0.78 \pm$ $0 \cdot 21$ ). There was, however, a highly significant reduction in migration between neonates and adult controls $(P<0.001)$. To exclude the possibility that this result was attributable to repeated testing of patients with particularly reduced migration, all tests on each patient were combined, the mean was taken, and the analysis was performed again. The reduction in migration, compared with adult controls, was again highly significant $(0.70 \pm 0.20$ and $0.75 \pm 0.16$ for autologous and control plasma respectively; $P<0.001$ ).

The neutrophil migration in cord blood from fullterm babies was not significantly different $(0.94 \pm$ $0 \cdot 14, P>0 \cdot 1)$ from that of adult controls $(1 \cdot 00 \pm$ $0 \cdot 12)$. Table 1 gives the results obtained according to

Table 1 Neutrophil migration in premature infants at various periods after delivery

\begin{tabular}{|c|c|c|c|c|}
\hline \multirow{2}{*}{$\begin{array}{l}\text { Postnatal } \\
\text { age } \\
\text { (days) }\end{array}$} & \multirow{2}{*}{$\begin{array}{l}\text { Number } \\
\text { of } \\
\text { patients }\end{array}$} & \multirow{2}{*}{$\begin{array}{l}\text { Number } \\
\text { of } \\
\text { tests }\end{array}$} & \multicolumn{2}{|c|}{$\begin{array}{l}\text { Mean neutrophilmigration } \pm \\
\text { I SD (as ratio of control) }\end{array}$} \\
\hline & & & $\begin{array}{l}\text { Autologous } \\
\text { plasma }\end{array}$ & $\begin{array}{l}\text { Control } \\
\text { plasma* }\end{array}$ \\
\hline $\begin{array}{c}1-7 \\
8-14 \\
15-21 \\
22-28 \\
29-42 \\
43-56 \\
57-70 \\
71-122\end{array}$ & $\begin{array}{r}15 \\
14 \\
10 \\
9 \\
9 \\
10 \\
7 \\
6\end{array}$ & $\begin{array}{r}16 \\
14 \\
10 \\
9 \\
13 \\
15 \\
12 \\
14\end{array}$ & $\begin{array}{l}0.56 \pm 0.23 \\
0.74 \pm 0.31 \\
0.83 \pm 0.28 \\
0.75 \pm 0.36 \\
0.87 \pm 0.32 \\
0.82 \pm 0.25 \\
0.67 \pm 0.22 \\
0.81 \pm 0.17\end{array}$ & $\begin{array}{l}0.66 \pm 0.25 \\
0.85 \pm 0.15 \\
0.79 \pm 0.18 \\
0.88 \pm 0.27 \\
0.82 \pm 0.21 \\
0.81 \pm 0.13 \\
0.67 \pm 0.21 \\
0.75 \pm 0.23\end{array}$ \\
\hline
\end{tabular}

* At no time of testing was there a significant difference between measurement in autologous and control plasmas ( $P$ always $>0.01$ ).

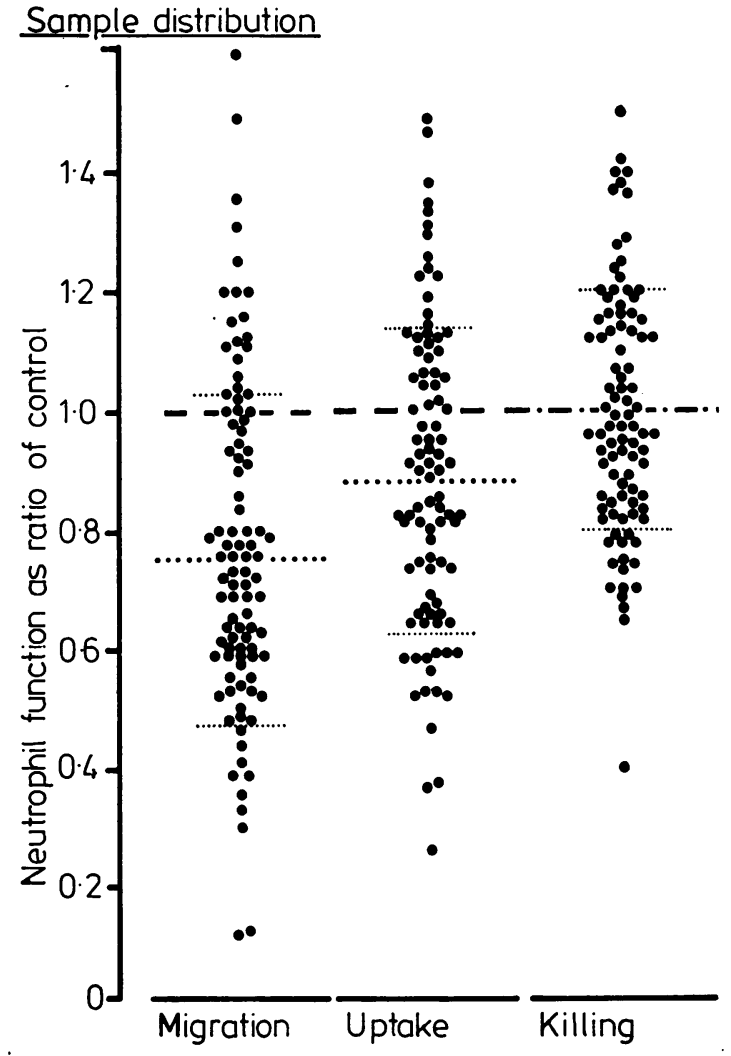

Fig. 1 Measurements of migration, uptake, and killing in 27 premature infants. Horizontal lines $=$ mean \pm $1 S D$.

the postnatal age of the premature infant. Migration was significantly impaired ( $P$ always $<0.01$ ) during the first and second weeks and from week 7 onwards; the latter was probably due to selection of particularly ill or immature infants.

Considerable variation in neutrophil migration was observed among the different patients tested sequentially. Of the 10 patients tested on four or more occasions, three improved and became normal after six to 13 weeks. In six of the remaining cases, no particular trend could be identified, neutrophil migration remaining substantially normal or persistently low. In one case, all functions fell to low levels shortly before death (Fig. 2).

\section{NEUTROPHIL UPTAKE}

In 92 samples from the 27 premature infants (Fig. 1), the mean candida uptake ratio was not significantly different $(P=0.19)$ between autologous $(0.88 \pm$ $0.26)$ and control $(0.85 \pm 0.23)$ plasma, but candida uptake was significantly reduced compared with 


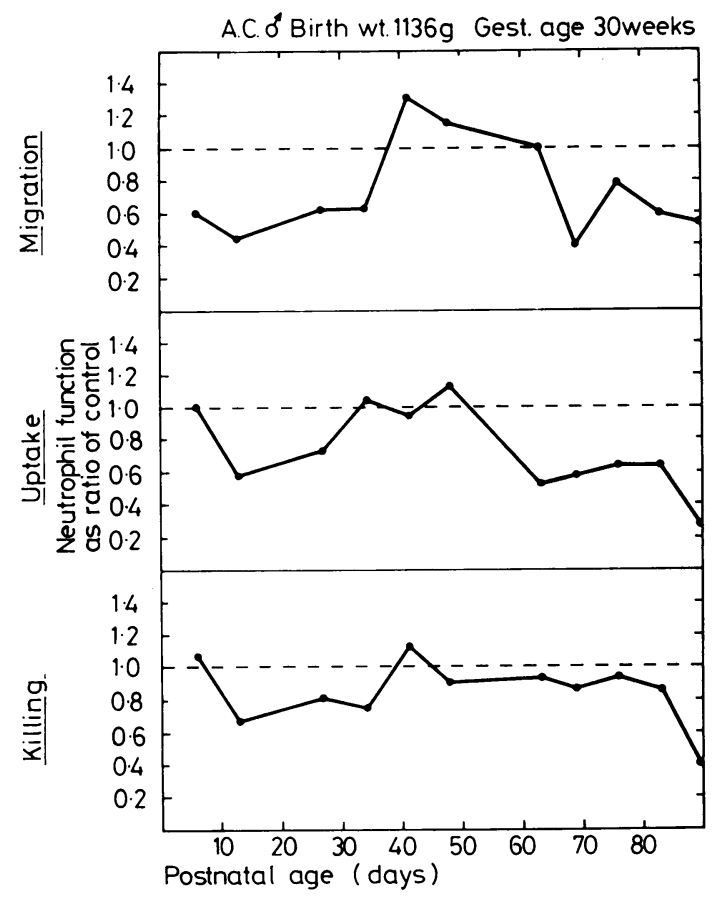

Fig. 2 Sequential measurements of neutrophil function in an infant who died aged 92 days of bronchopulmonary dysplasia after ventilator therapy for hyaline membrane disease. Terminally, he experienced periods of hypoxaemia and had a persistent respiratory acidosis.

adult controls $(\mathrm{P}<0.001)$. The means for individual patients were reanalysed as before, and uptake was again significantly reduced $(\mathrm{P}<0.001)$ in both autologous $(0.85 \pm 0 \cdot 18)$ and control $(0.86 \pm 0 \cdot 16)$ plasmas. Candida uptake in normal neonates was not significantly different from that observed in adult controls $(1.03 \pm 0 \cdot 12, \mathrm{P}>0.2$; control $1.00 \pm 0.08)$. Although uptake was significantly reduced in the whole group when patients were analysed according to the period after delivery, significantly reduced uptake $(\mathrm{P}<0.01)$ was observed only from day 57 onwards (Table 2).

Eight patients were tested sequentially on four or more occasions. In three patients, neutrophil uptake remained substantially normal; all had uncomplicated postnatal periods. In three, progressive impairment of phagocytosis was observed; two of these patients continued to make uninterrupted progress, but one died after a prolonged period of respiratory acidosis (Fig. 2). In the two remaining patients, uptake fluctuated but did not correlate with the clinical state.
Table 2 Neutrophil uptake of candida in premature infants at different periods after delivery

\begin{tabular}{|c|c|c|c|c|}
\hline \multirow{2}{*}{$\begin{array}{l}\text { Postnatal } \\
\text { age } \\
\text { (days) }\end{array}$} & \multirow{2}{*}{$\begin{array}{l}\text { Number } \\
\text { of } \\
\text { patients }\end{array}$} & \multirow{2}{*}{$\begin{array}{l}\text { Number } \\
\text { of } \\
\text { tests }\end{array}$} & \multicolumn{2}{|c|}{$\begin{array}{l}\text { Mean neutrophil uptake } \\
S D \text { (as ratio of control) }\end{array}$} \\
\hline & & & $\begin{array}{l}\text { Autologous } \\
\text { plasma }\end{array}$ & $\begin{array}{l}\text { Control } \\
\text { plasma* }\end{array}$ \\
\hline $1-7$ & 12 & 13 & $0.82 \pm 0.34$ & $0.87 \pm 0.22$ \\
\hline $8-14$ & 16 & 16 & $1.06 \pm 0.25$ & $1.03+0.15$ \\
\hline $15-21$ & 10 & 10 & $0.96 \div 0.19$ & $0.90 \pm 0.16$ \\
\hline $22-28$ & 6 & 6 & $0.91 \pm 0.26$ & $0.96 \div 0.07$ \\
\hline $29-42$ & 9 & 12 & $0.87+0.25$ & $0.87 \doteqdot 0.19$ \\
\hline $43-56$ & 8 & 13 & $1.05 \pm 0.19$ & $0.95 \pm 0.15$ \\
\hline $57-70$ & 7 & 12 & $0.63 \pm 0.16$ & $0.57 \pm 0.23$ \\
\hline $71-122$ & 6 & 10 & $0.70+0.20$ & $0.68 \div 0.23$ \\
\hline
\end{tabular}

*At no time of testing was there a significant difference between measurement in autologous and control plasmas ( $P$ always $>0.01$ ).

NEUTROPHIL KILLING

Compared with adult controls, no significant reduction of candida killing was observed in the group as a whole (Fig. 1); in 93 samples the mean killing was $1.00 \pm 0.20$ and $0.98 \pm 0.18$ in autologous and control plasma respectively $(\mathrm{P}>0 \cdot 8, \mathrm{P}>0 \cdot 1)$. When repeated samples from the same individual were considered together and the series was reanalysed, candida killing was again normal $(0.99 \pm 0.14$ and $0.98 \pm 0.14$ in autologous and control plasma; $P>0.5$ and $P>0.2$ ).

Neutrophil killing was normal until 10 weeks after delivery (Table 3 ), but in the small group of six patients studied after this period reduced killing was observed; two of these patients were very ill and one of these died. Neutrophil killing in full-term infants was normal compared with adult controls $(0.99 \pm$ $0 \cdot 12$, P > 0.8; control $1 \cdot 00 \pm 0 \cdot 16$ ).

Eight cases were examined sequentially on four or more occasions; in five of these, killing was always within $20 \%$ of normal, and four made uncomplicated clinical progress. In two, killing was normal, but then became reduced; in one this occurred immediately before death (Fig. 2), while in the other patient re-

Table 3 Neutrophil killing of candida in premature infants at different periods after delivery

\begin{tabular}{|c|c|c|c|c|}
\hline \multirow{2}{*}{$\begin{array}{l}\text { Postnatal } \\
\text { age } \\
\text { (days) }\end{array}$} & \multirow{2}{*}{$\begin{array}{l}\text { Number } \\
\text { of } \\
\text { patients }\end{array}$} & \multirow{2}{*}{$\begin{array}{l}\text { Number } \\
\text { of } \\
\text { tests }\end{array}$} & \multicolumn{2}{|c|}{$\begin{array}{l}\text { Mean neutrophil killing } \pm 1 \\
S D \text { (as ratio of contro })\end{array}$} \\
\hline & & & $\begin{array}{l}\text { Autologous } \\
\text { plasma }\end{array}$ & $\begin{array}{l}\text { Control } \\
\text { plasma* }\end{array}$ \\
\hline $1-7$ & 14 & 15 & $0.96 \pm 0.18$ & $0.93 \pm 0.17$ \\
\hline $8-14$ & 15 & 15 & $0.93 \pm 0.18$ & $0.99 \pm 0.21$ \\
\hline $15-21$ & 8 & 8 & $1.06 \pm 0.19$ & $1.06 \pm 0.18$ \\
\hline $22-28$ & 7 & 7 & $1.06 \pm 0.16$ & $0.98 \pm 0.16$ \\
\hline $29-42$ & 9 & 12 & $0.98 \pm 0.15$ & $0.96 \pm 0.08$ \\
\hline $43-56$ & 8 & 13 & $1.08 \pm 0.24$ & $1.11 \pm 0.16$ \\
\hline $57-70$ & 7 & 12 & $1.01 \pm 0.23$ & $0.95 \pm 0.18$ \\
\hline $71-122$ & 6 & 10 & $0.83 \pm 0.16$ & $0.87 \pm 0.14$ \\
\hline
\end{tabular}

*At no time of testing was there a significant difference between measurement in autologous and control plasmas ( $P$ always $>\mathbf{0 . 0 1}$ ). 
duced killing recurred at times of intravenous cannula infections. In one patient, consistently increased killing was observed; this patient was an uncomplicated premature infant.

CORRELATION BETWEEN MIGRATION, UPTAKE, AND KILLING

Although the significance-of-correlation test seemed to indicate some correlation between migration and uptake ( $\mathrm{P}<0.01, \mathrm{r}=0.27)$, the actual plots of the data showed a very large residual variance. There was no correlation between migration and killing $(P=0 \cdot 17$ and $r=0 \cdot 1)$ or between phagocytosis and killing $(\mathrm{P}=0.04, \mathrm{r}=0.22)$.

The correlation between tests performed in autologous and control plasmas was highly significant (for migration, $r=0.62$ and $P<0.00001$; for uptake, $r=0.79$ and $P<0.00001$; for killing, $r=0.66$, $P<0.00001)$.

CORRELATION BETWEEN NEUTROPHIL

FUNCTION AND HAEMOGLOBIN

There was no correlation between the haemoglobin levels and either neutrophil migration $(P=0.2$, $r=0.1)$ or neutrophil killing $(P=0.025, r=0.24)$. However, there was significant correlation between haemoglobin level and phagocytosis $(\mathrm{P}<0.001, \mathrm{r}=$ $0 \cdot 41$ ).

\section{Discussion}

The present study showed a consistent reduction in non-directed neutrophil migration in premature infants, especially during the first two weeks of extrauterine life. Migration was similarly reduced in both autologous and control adult plasmas, and the defect is therefore attributable to an intrinsic abnormality of the neutrophil. Non-directed migration does not seem to have been studied previously in premature, low-birth-weight infants but it has been reported to be normal in full-term neonates. ${ }^{13}$ Directed migration (chemotaxis) has received more attention, and most studies have shown reductions, not corrected by control plasma, in both full-term 1013161722 and premature infants. ${ }^{18} 22$

In the premature infants considered as a group, neutrophil phagocytosis was significantly reduced. Uptake was similarly reduced in the presence of autologous and control plasmas, and is, therefore, presumably the result of an intrinsic neutrophil phagocytic defect. In contrast, most previous studies of neutrophil phagocytosis in premature infants have yielded normal results, 81521 although there have been reports of reduced ${ }^{4} 9$ or even increased ${ }^{5}$ uptake. Similarly, in full-term infants most authors have found normal uptake, 811152021 although there have again been reports of reduced phagocytosis. ${ }^{39}$ It is not clear why we have demonstrated an overall reduction in phagocytosis when many previous studies have failed to demonstrate such a defect. The discrepancy may, however, be attributable to the technical limitations of previous methods since the whole-blood technique used in the present study is highly sensitive and reproducible. 2324

Like some authors, ${ }^{811} 21$ but unlike others, 51518 we found neutrophil killing in premature infants to be normal. The discrepancies in the literature may again be attributable to technical differences in such factors as test organism, leucocyte/microorganism ratio, etc.

Serial testing of neutrophil function showed evidence of improved uptake and migration after one and two weeks respectively. Uptake improved to normal levels, but migration remained somewhat impaired. After eight weeks there was evidence of deterioration in both these functions. After 10 weeks killing also appeared to be reduced. At these later postnatal ages there was a selection of sick or particularly low-birth-weight infants. Impairment of neonatal neutrophil function under stress conditions has been well described, 8141821 and the selection of sick patients after eight weeks probably accounts for the deteriorating function we observed at this time. Serial study of individual patients lent support to this explanation.

No previous studies have investigated simultaneously migration, phagocytosis, and killing in full-term or premature neonates, and the correlation between these functions is therefore of some interest. Our study showed a possible weak correlation between migration and uptake, but there appeared to be no relationship between migration and killing or between phagocytosis and killing.

Since anaemia in young children has been reported to be associated with impaired bactericidal activity, ${ }^{26}$ we examined the relationship between haemoglobin level and neutrophil function. There was no correlation between haemoglobin level and either migration or killing, but reduced haemoglobin levels were associated with reduced phagocytosis. Such reduced phagocytosis may account for the impaired bactericidal activity observed by Srikantia et $a .^{26}$ in anaemic children.

The biochemical basis of the impaired migration and phagocytosis but normal killing that we have demonstrated in the neutrophils of premature infants requires further investigation, but these abnormalities, together with the range of metabolic disturbances previously described, ${ }^{1}$ provide ample evidence for a defect of neutrophil host-defence in premature infants. 
Thanks are due to Mr D Lowe and Mr D Girmes for statistical help, to Dr J Fletcher for the supply of Candida guilliermondii, and to Miss $\mathbf{P}$ Richardson and Miss R-MLA Nicholls.

\section{References}

${ }^{1}$ Boxer LA. Immunological function and leucocyte disorders in newborn infants. Clin Haematol 1978;7:123-46.

${ }^{2}$ Miller ME. Phagocyte function in the neonate: selected aspects. Pediatrics 1979;64 (5 pt 2 Suppl):709-12.

${ }^{3}$ Matoth Y. Phagocytic and ameboid activities of the leucocyte in the newborn infant. Pediatrics 1952;9:748-54.

${ }^{4}$ Gluck L, Silverman WA. Phagocytosis in premature infants. Pediatrics $1957 ; 20: 951-7$.

${ }^{5}$ Cocchi P, Marianelli L. Phagocytosis and intracellular killing of pseudomonas aeruginosa in premature infants. Helv Paediatr Acta 1967;1:110-8.

- Coen R, Grush O, Kauder E. Studies of bactericidal activity and metabolism of the leucocyte in full term neonates. J Pediatr 1969;75:400-6.

${ }^{7}$ Dossett JH, Williams RC Jr, Quie PG. Studies on interaction of bacteria, serum factors and polymorphonuclear leucocytes in mothers and newborn. Pediatrics 1969;44: 49-57.

${ }^{8}$ Forman ML, Stiehm ER. Impaired opsonic activity but normal phagocytosis in low-birth-weight infants. New Engl J Med 1969;281:926-31.

- Miller ME. Phagocytosis in the newborn infant: humoral and cellular defects. $J$ Pediatr 1969;74:255-9.

${ }^{10}$ Miller ME. Chemotactic function in the human neonate: humoral and cellular aspects. Pediatr Res $1971 ; 5: 487-92$.

11 McCracken GH Jr, Eichenwald HF. Leucocyte function and the development of opsonic and complement activity in the neonate. Am J Dis Child 1971;121:120-6.

12 Anderson DC, Pickering LK, Feigin RD. Leucocyte function in normal and infected neonates. $J$ Pediatr $1974 ; 85: 420-5$.

${ }^{13}$ Miller ME. Developmental maturation of human neutrophil motility and its relationship to membrane deformability. In: Bellanti JA, Dayton DH, eds. The phagocytic cell in host resistance. New York: Raven Press, 1975 , 295-307.

14 Wright WC Jr, Ank BJ, Herbert J, Stiehm ER. Decreased bactericidal activity of leucocyte of stressed newborn infants. Pediatrics 1975;56:579-84.

${ }^{15}$ Xanthou M, Valassi-Adam E, Kintzonilou E, Matsaniotis N. Phagocytosis and killing ability of Candida albicans by blood leucocytes of healthy term and preterm babies. Arch Dis Child 1975;50:72-5.

${ }^{16}$ Klein RB, Fischer TJ, Gard SE, Biberstein M, Rich KC, Stiehm ER. Decreased mononuclear and polymorphonuclear chemotaxis in human newborns, infants and young children. Pediatrics 1977;60:467-72.

17 Pahwa SG, Pahwa R, Grimes E, Smithwick E. Cellular and humoral components of monocyte and neutrophil chemotaxis in cord blood. Pediatr Res 1977;11:677-80.

${ }^{18}$ Laurenti F, La Greca, Ferro R, Bucci G. Transfusion of polymorphonuclear neutrophils in a premature infant with klebsiella sepsis. Lancet 1978;ii:11-2.

${ }^{19}$ Miler I, Vondráčvek J, Hromádková L. The decreased in vitro chemotactic activity of polymorphonuclear leucocytes of newborns and infants. Folia Microbiol 1979;24: 247-52.

${ }^{20}$ Mills EL, Thompson T, Bjorksten B, Filipovich D, Quie PG. The chemiluminescence response and bactericidal activity of polymorphonuclear neutrophils from newborns and their mothers. Pediatrics 1979;63:429-34.

${ }^{21}$ Shigeoka AO, Santos JI, Hill HR. Functional analysis of neutrophil granulocytes from healthy, infected and stressed neonates. J Pediatr 1979;95:454-60.

${ }^{22}$ Laurenti F, Ferro R, Marzetti G, Rossini M, Bucci G. Neutrophil chemotaxis in pre-term infants with infections. $J$ Pediatr 1980;96:468-70.

${ }^{23}$ Al-Hadithy $\mathrm{H}$, Addison IE, Goldstone AH. Use of whole blood in the measurement of neutrophil migration. J Clin Pathol 1981 ;34:158-62.

${ }^{24}$ Al-Hadithy $\mathrm{H}$, Addison IE, Goldstone AH. A rapid whole blood technique for assessment of neutrophil phagocytosis and killing. Clin Lab Haemat in press.

${ }^{25}$ Sasaki M, Looman B, Terasaki PI. Miniaturised whole blood ADCC assay of depressed effector activity in cancer patients. Tissue Antigens 1980;15:225-30.

${ }^{26}$ Srikantia SG, Prasad JS, Bhaskaram C, Krishnamachari KAVR. Anaemia and immune response. Lancet 1976;i: 1037-9.

Requests for reprints to: Dr AH Goldstone, Department of Haematology, University College Hospital, Gower Street, London WC1E 6AU. 